\title{
ASSESSMENT OF THE SEVERITY OF UNSTEADY MACH NUMBER EFFECTS IN A 3-STAGE TRANSONIC COMPRESSOR
}

\author{
Anthony Dent; Liping Xu \\ Whittle Laboratory \\ University of Cambridge \\ $1 \mathrm{JJ}$ Thomson Avenue \\ Cambridge, CB3 ODY, UK \\ Email:ad540@cam.ac.uk
}

\author{
Roger Wells \\ Siemens Industrial Turbomachinery Ltd \\ Ruston House \\ Waterside South \\ Lincoln, LN5 7FD, UK
}

\begin{abstract}
In this paper results from steady and unsteady CFD simulations of an industrial transonic compressor are compared, in order to gain a better understanding of the cause of the differences in the predicted efficiencies between the steady and unsteady simulations. Initially the first stage is simulated as an isolated compressor stage with inlet guide vanes in order to analyse the effect of individual blade rows on the stage performance. It is found that the rotor efficiency is lower for steady simulations than for unsteady simulations due to stronger shock waves. The stator efficiency is greater in the steady simulations due to not being able to model the interaction of the rotor wakes with the stator blade leading edge and boundary layers. Greater variation between steady and unsteady predictions is found at higher operating speeds. In the 3-stage unsteady simulations, the front stage efficiency characteristic is the same as the efficiency calculated from the isolated unsteady simulations. This shows that the unsteady pressure potential propagating from the downstream stages has no significant effect on the front stage efficiency meaning that the designer does not need to give great consideration to the downstream blade rows when predicting the characteristics of the front stage.
\end{abstract}

\footnotetext{
*Address all correspondence to this author.
}

\section{INTRODUCTION}

The flow in a multi-blade row compressor is inherently unsteady, due to rotor-stator interactions, meaning that a number of assumptions need to be made in order to model the flow in a steady CFD simulation. For example, one could assume the flow to be steady relative to each blade row and use a mixing plane between the blade rows to transfer mixed out flow properties across the blade row interface [1]. This means that physical flow features, such as the unsteady rotor-stator interactions, are not being modelled which leads to less accurate predictions of the losses and less accurate predictions of the compressor performance.

Despite this, steady simulations are far more common in compressor design cycles than unsteady simulations because unsteady simulations typically costs $1-3$ orders of magnitude more to perform than steady simulations. This means that while it may be feasible to perform unsteady simulations at the nominal design point, it is often not possible to perform unsteady simulations at a great number of off-design conditions. It is therefore useful for the designer to have an understanding of which operating conditions are likely to have a significant variation in the overall performance predictions between steady and unsteady simulations. This gives the designer more knowledge about where on the operating map the steady simulation assumptions break down and therefore at which operating conditions to target unsteady simulations.

In recent years the use of unsteady CFD has become increasingly common as computational times have decreased. A good number of unsteady simulations have been reported on tran- 


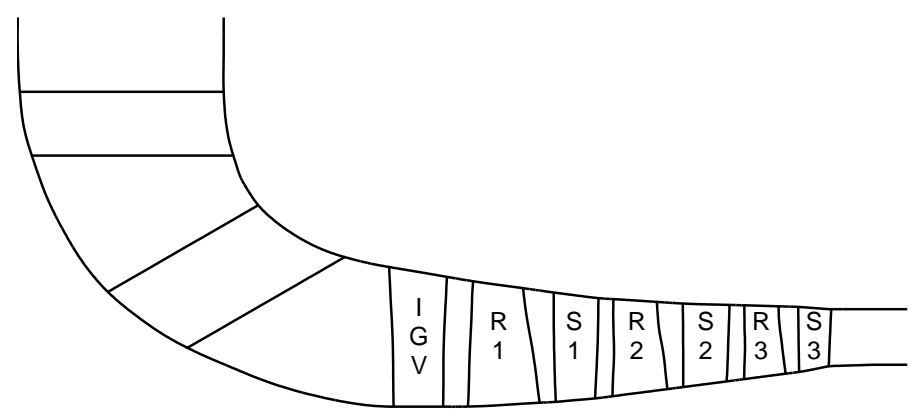

FIGURE 1: CFD DOMAIN

sonic compressors, however, the majority of the work reported in the literature has been performed on single stage machines and the efficiency almost always considered only for an entire stage rather than breaking down the losses between individual blade rows. A number of publications make a comparison between steady and unsteady simulations for transonic compressors. Some of these present results from multistage calculations but only at design speed [2-5] while others present results at offdesign speeds but only for a single stage [6]. Others compare steady and unsteady results but only for a single stage and at design speed [7-9]. Further single stage unsteady simulations have been presented for part speed calculations [10-12] and at design speed [13-17], including Large Eddy Simulations (LES) [18], however, none of these compare the unsteady simulations to steady simulations.

Presented in this paper is a comparison between steady and unsteady CFD results by performing a CFD investigation on a 3stage industrial transonic compressor [19]. The overall efficiency is broken down into individual blade row efficiencies so that it can be determined where the efficiency predictions for steady and unsteady simulations differ. Results are presented from isolated simulations of the front 1.5 stages of the compressor, with an analysis of each blade row individually for the design speed. Then results for off-design speeds are presented to show how the difference between steady and unsteady simulations changes as the speed varies. Finally, results are presented from multistage simulations to assess the impact of the downstream blade rows on the front stage efficiency predictions.

\section{COMPUTATIONAL APPROACH}

All the CFD simulations presented were performed using the Turbostream solver [20]. Turbostream is a Reynolds-Averaged Navier-Stokes (RANS), structured multi-block solver based on Denton's latest solver TBLOCK [21]. All simulations assumed fully turbulent boundary layers and used the Spalart-Allmaras turbulence model [22] with adaptive wall functions. Steady calculations of multiple blade rows used a mixing plane between
TABLE 1: MESH PARAMETERS

\begin{tabular}{cccc}
\hline Mesh & $y^{+}$ & Nodes per 1st Rotor Passage & Total Nodes \\
\hline A & $>30$ & $0.5 \times 10^{6}$ & $4.5 \times 10^{6}$ \\
B & $5-15$ & $0.6 \times 10^{6}$ & $5.3 \times 10^{6}$ \\
C & $\leq 5$ & $1.2 \times 10^{6}$ & $9.7 \times 10^{6}$ \\
D & $\leq 5$ & $1.6 \times 10^{6}$ & $11.1 \times 10^{6}$ \\
E & $\leq 5$ & $6.4 \times 10^{6}$ & $52.8 \times 10^{6}$ \\
\hline
\end{tabular}

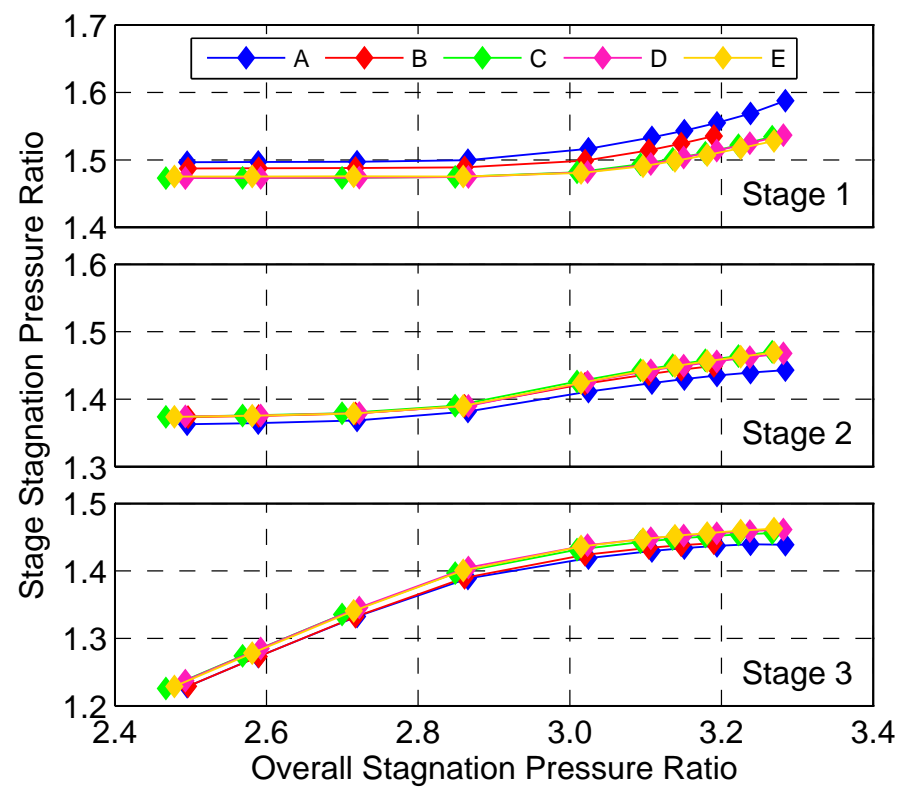

FIGURE 2: STAGE PRESSURE RATIOS PREDICTIONS FOR MESHES A to E

adjacent blade rows. Unsteady (URANS) calculations used the dual time-stepping method [23] with 100 time steps per first stage rotor passing. The CFD domain for the 3-stage calculations includes an inlet duct with two rows of support struts followed by an Inlet Guide Vane (IGV) row and three rotor-stator stages. The 3-stage domain is shown in Fig. 1. The domain for the single stage calculations removes the middle and downstream stages (R2, S2, R3, S3) and a parallel exit duct is added downstream of stator 1 . The grid is generated using NUMECA Autogrid with $\mathrm{O}$ meshes around the blades and $\mathrm{H}$ meshes upstream, downstream and in the blade passage.

The mesh density required was established by calculating the 3-stage design speed characteristics on five different meshes ranging from 4.5 million nodes to 52.8 million nodes. Details of 


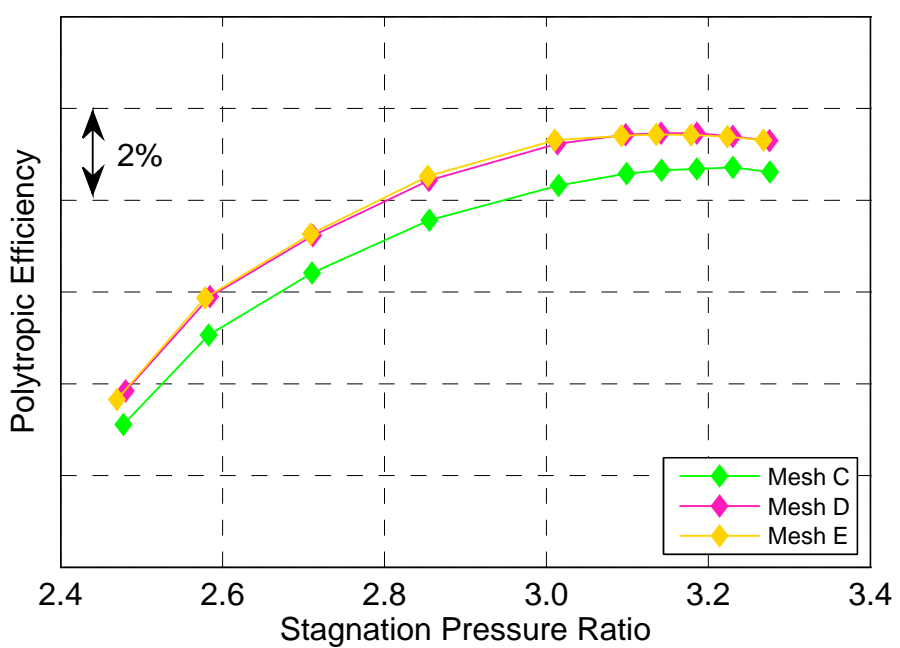

FIGURE 3: OVERALL EFFICIENCY PREDICTIONS FOR MESHES C to E

the meshes are given in Tab. 1. In a multi-stage calculation the most fundamental feature to correctly predict is the stage matching. Figure 2 shows the individual stage stagnation pressure ratios plotted against the overall stagnation pressure ratio on the design speed line for each of the five meshes. It can be seen that Meshes A and B predict a different stage matching than the finer meshes, particularly for stage 1 . From this it can be stated that it is important to have the first grid point in the laminar sub layer of the boundary layer by ensuring the first grid point is at a $y^{+}$ of less than five. Having established mesh independence to the stage matching, the predicted overall efficiency is compared in Fig. 3. Mesh C is seen to predict a lower efficiency while Meshes $\mathrm{D}$ and $\mathrm{E}$ give the same efficiency prediction. It has been demonstrated that the results are mesh independent between Meshes D and $\mathrm{E}$ so the rest of this paper will present results using Mesh D. In addition this mesh was found to transfer the blade wakes through the sliding planes well and a high mesh density has been used around the leading edges in order to capture the variations in the unsteady flow. (Excellent transfer of information across the sliding planes can be seen in the static pressure plot of Fig. 19.)

In order to perform unsteady simulations of multiple blade rows with different blade counts it is necessary to model multiple blade passages in each blade row. It was decided to model one quarter of the annulus by adjusting the blade counts of some blade rows, as detailed in Tab. 2 , so that the domain was periodic. In order to minimise the effect of adjusting the blade count on the performance predictions it is necessary to minimise any effect on the stage matching so the blade sections were scaled to maintain a constant pitch-to-chord ratio. In addition the axial position of each blade row was moved so that the ratio of the chord to the upstream inter-blade-row gap was maintained con-
TABLE 2: INDIVIDUAL ROW BLADE COUNTS

\begin{tabular}{cccc}
\hline Blade Row & $\begin{array}{c}\text { Real } \\
\text { Blade Counts }\end{array}$ & $\begin{array}{c}\text { Adjusted } \\
\text { Blade Counts }\end{array}$ & \% Change \\
\hline IGV & 26 & 24 & $8 \%$ \\
Rotor 1 & 21 & 20 & $5 \%$ \\
Stator 1 & 32 & 32 & $0 \%$ \\
Rotor 2 & 23 & 24 & $4 \%$ \\
Stator 2 & 32 & 32 & $0 \%$ \\
Rotor 2 & 27 & 28 & $4 \%$ \\
Stator 2 & 44 & 44 & $0 \%$ \\
\hline
\end{tabular}

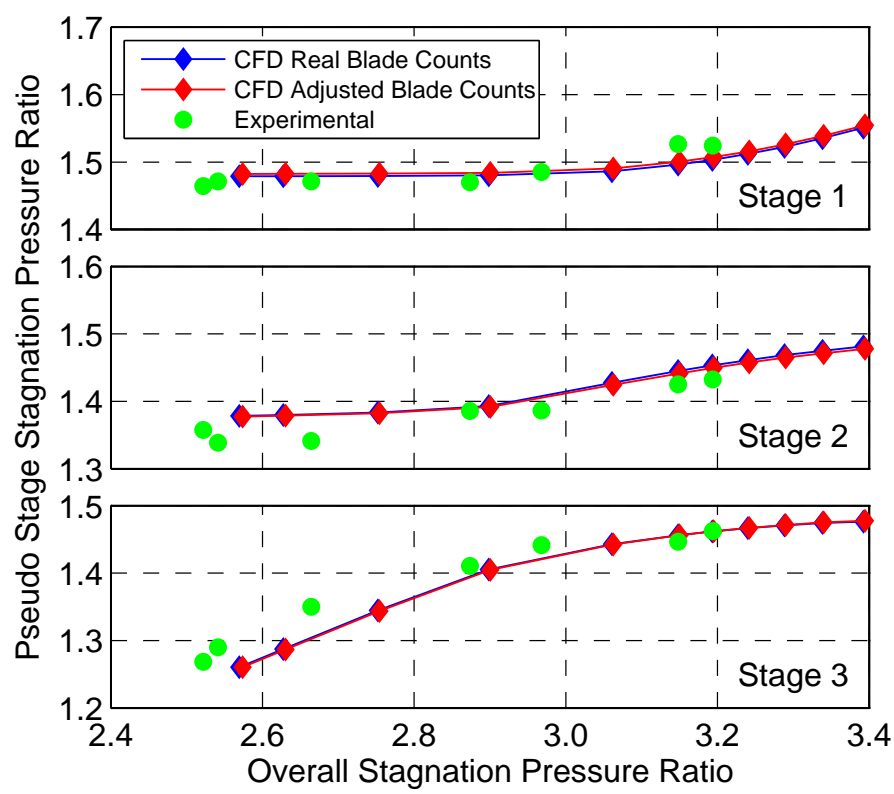

FIGURE 4: INDIVIDUAL STAGE PRESSURE RATIOS FOR REAL AND ADJUSTED BLADE COUNTS WITH EXPERIMENTAL DATA

stant. The outcome of these adjustments is that the differences in the stage matching, between the real blade counts and the quarter annulus adjusted blade counts, are minimal, as shown in Fig. 4. The results presented in Fig. 4 are calculated from single passage, steady simulations using real and adjusted blade counts. The pressure ratios presented are pseudo stage pressure ratios because each pressure ratio is calculated from pressures taken from the leading edge of the stationary blade rows and represents an 


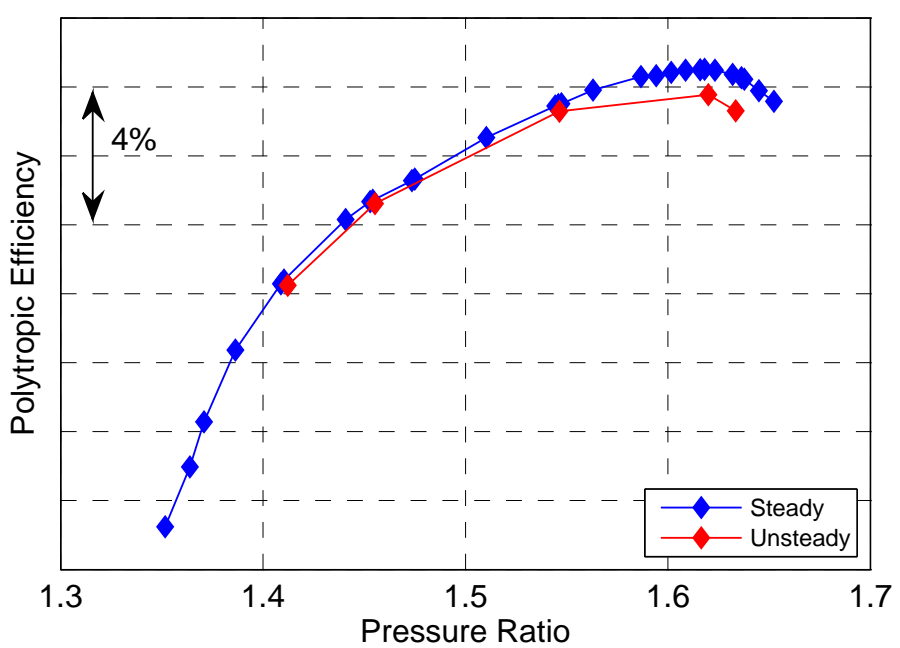

FIGURE 5: EFFICIENCY PREDICTIONS FOR 1.5 STAGE CALCULATIONS AT DESIGN SPEED

IGV-rotor or stator-rotor pair. This allows direct comparison of the CFD results and the experimental results by using measurements from the IGV and stator leading edge instrumentation in the test rig. The experimental results are also shown in Fig. 4 and show good agreement with the CFD results. Stage one is well characterised by the CFD simulations across the whole range and stages 2 and 3 are also well predicted at and above the design pressure ratio of 3 . At lower pressure ratios there is a small mismatch between the CFD and experimental results although the general trends are still well captured. While not shown in this paper, further validation of the results has been obtained using ANSYS CFX with the $k-\varepsilon$ and Shear Stress Transport turbulence models and it was found that the same flow features where captured in both CFD codes. All this gives good confidence in the CFD results. The rest of this paper will present results calculated using the adjusted blade counts in order to provide a fair comparison between steady and unsteady calculations. Results are calculated using mass averaged properties and unsteady results are then time averaged over at least one, quarter annulus, cycle.

\section{DESIGN SPEED ANALYSIS OF FRIST STAGE}

Figure 5 shows the polytropic efficiency calculated from steady and unsteady simulations of the front stage (including the IGV blade row) at the design speed. The unsteady simulations predict a lower efficiency across the whole characteristic and the difference between the predicted efficiency of the steady and unsteady simulations increases with the pressure ratio as shown in Tab. 3. In order to understand this variation it is helpful to look at the efficiency of the individual blade rows. The efficiency for individual blade rows is shown in Fig. 6 where blade efficiency
TABLE 3: DIFFERENCE IN POLYTROPIC EFFICIENCY BETWEEN STEADY AND UNSTEADY CALCULATIONS

\begin{tabular}{cc}
\hline Pressure Ratio & $\Delta \eta_{p}$ \\
\hline 1.41 & 0.05 \\
1.46 & 0.06 \\
1.55 & 0.16 \\
1.62 & 0.74 \\
1.63 & 1.05 \\
\hline
\end{tabular}

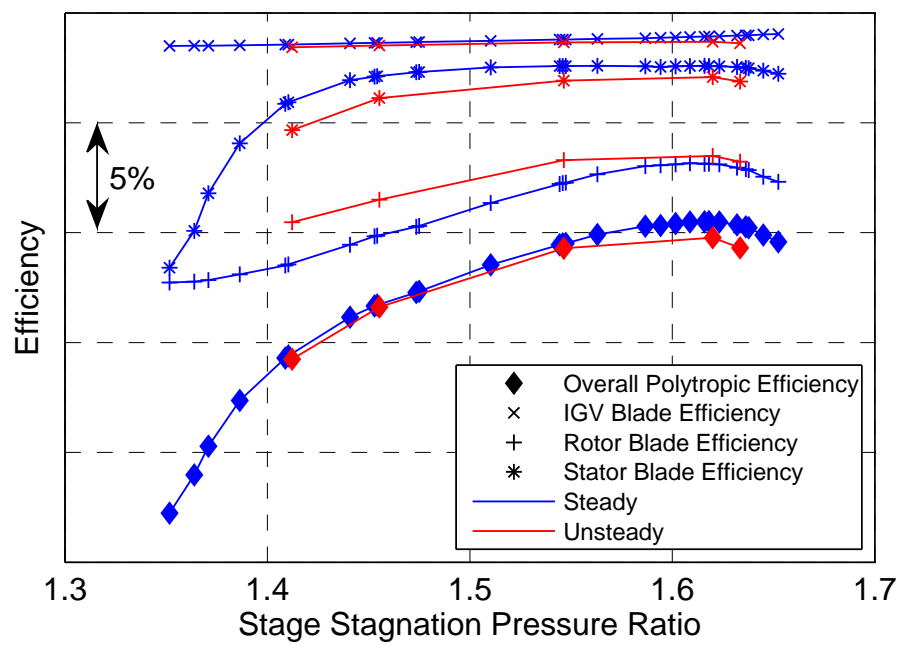

FIGURE 6: EFFICIENCY PREDICTIONS FOR INDIVIDUAL BLADE ROWS AT DESIGN SPEED

is defined in Eqn. (1) as shown by Denton [24]. It can be seen that the variation in the single stage efficiency between steady and unsteady simulations is due to a variation in the efficiency within different blade rows. Despite the single stage results having a small efficiency delta (defined in Eqn. (2)) at lower pressure ratios, it is seen in Fig. 6 that this is only because the efficiency deltas within the rotor and stator blade rows cancel out each other. At higher pressure ratios the steady and unsteady rotor efficiencies start to converge while the stator efficiency prediction is still lower for the unsteady calculation. This, combined with the slight increase in steady simulation IGV efficiency, leads to a greater single stage efficiency delta at higher pressure ratios.

$$
\eta_{\text {blade }}=1-\frac{\bar{T}_{\text {stage outlet }}\left(\bar{s}_{\text {blade inlet }}-\bar{s}_{\text {blade outlet }}\right)}{\Delta \bar{h}_{\text {stage }}}
$$




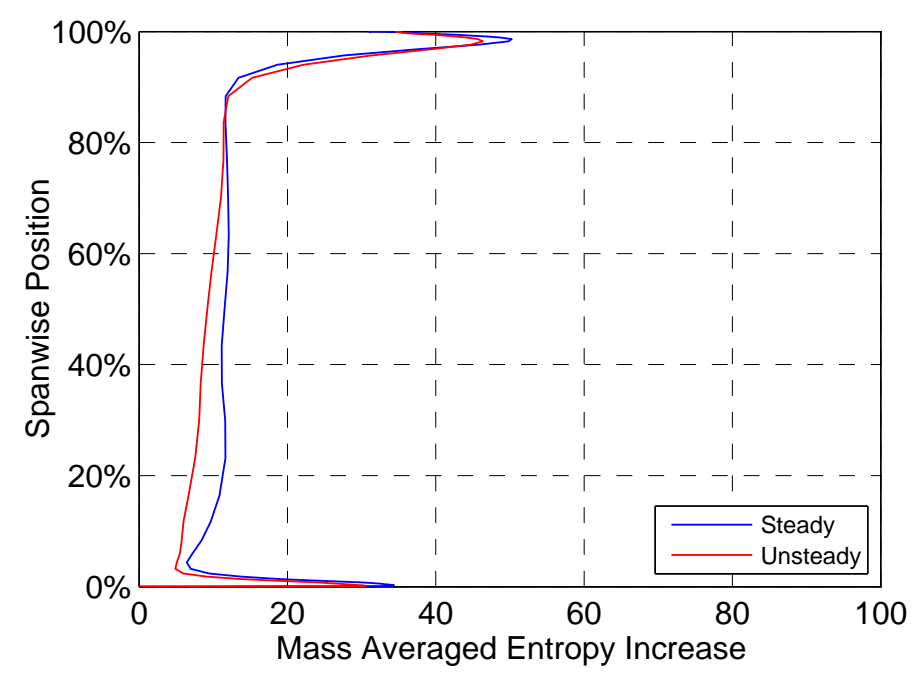

FIGURE 7: ENTROPY INCREASE ACCROSS ROTOR FOR PRESSURE RATIO OF 1.41

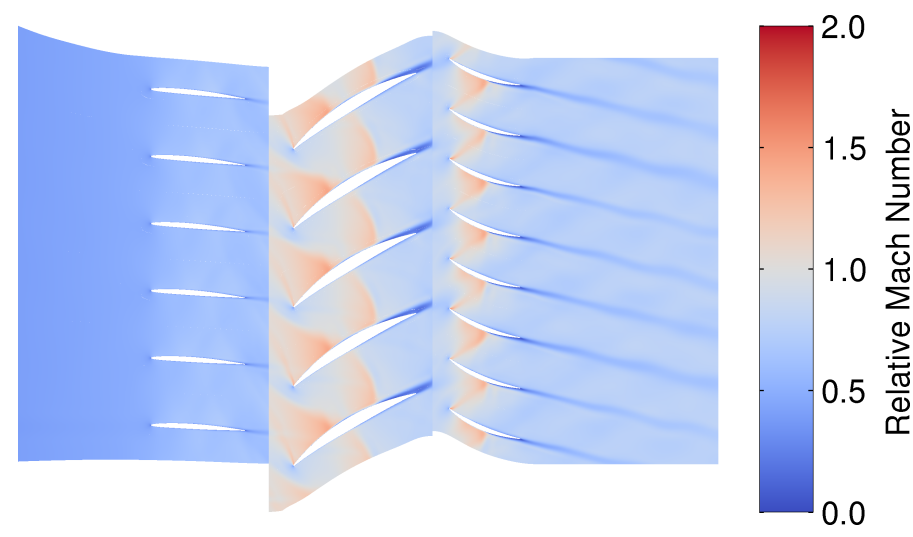

FIGURE 8: INSTANTANEOUS UNSTEADY RELATIVE MACH NUMBER AT 20\% SPAN FOR PRESSURE RATIO OF 1.41

$$
\Delta \eta=\eta_{\text {steady }}-\eta_{\text {unsteady }}
$$

\section{Rotor Efficiency}

The rotor has the greatest variation in efficiency delta compared to the other blade rows and varies from a negative delta (unsteady simulation has a higher efficiency) of $2.0 \%$ at the lowest pressure ratio, to just $0.3 \%$ near stall. In order to investigate the greatest efficiency delta for the rotor, which occurs at the a pressure ratio of 1.41 , the spanwise distribution of entropy increase through the rotor is plotted in Fig. 7. Results are plotted across the span and show a steady and unsteady simulation of the same pressure ratio. The greatest discrepancy between the

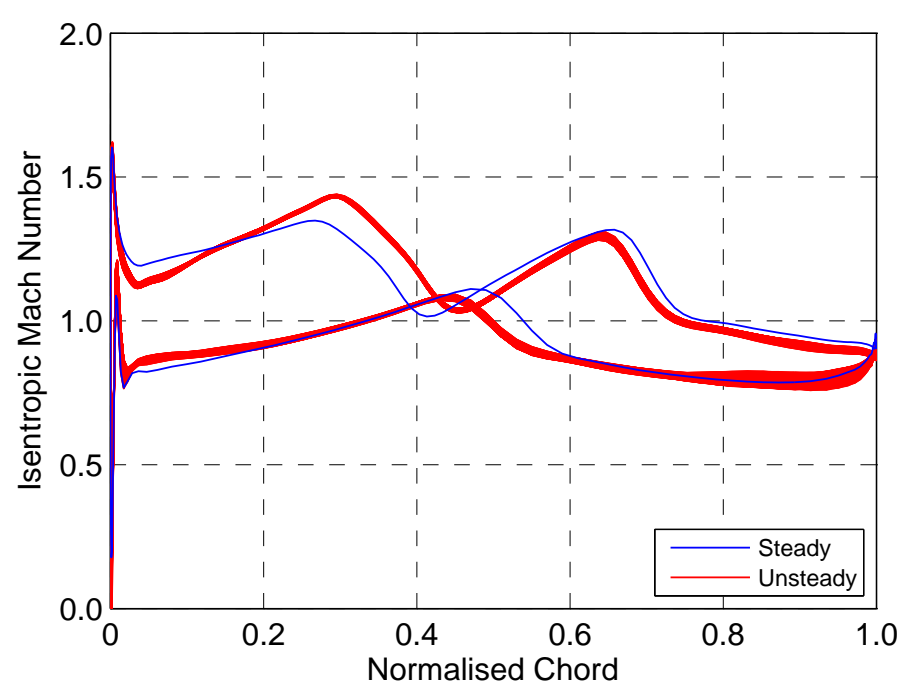

FIGURE 9: ROTOR SURFACE ISENTROPIC MACH NUMBER AT 20\% SPAN FOR PRESSURE RATIO OF 1.41

steady and unsteady results can be seen to occur in the lower half of the span with the greatest difference occurring at around $20 \%$ of span. Figure 8 shows the instantaneous relative Mach number for the unsteady simulation at a span of $20 \%$. At this operating condition the rotor has a leading edge shock and a passage shock. The passage shock is located quite far into the rotor passage as the operating pressure ratio is low and the rotor is choked. It can be shown that the position of the rotor passage shock is causing the greater entropy increase in the steady calculation. This is seen in Fig. 9 which shows the isentropic Mach number on the blade surface for the rotor at $20 \%$ span. The unsteady results at multiple instantaneous points from across a complete cycle are plotted in order to show the variation of the results. This shows that the passing of the IGV wakes has only a very small effect on the location of the shock structures and that the passage shock moves by less than $1 \%$ of the rotor chord throughout the cycle. Figure 9 shows that the passage shock position on the pressure and suction surfaces is further towards the trailing edge for the steady simulation than for the unsteady simulation. This means the rotor is operating more choked in the steady calculation and the shock Mach number is higher leading to greater loss and lower efficiency. The higher shock Mach number in the steady calculation can also be seen in Fig. 9.

In the centre of the passage an entropy analysis also shows that the shock Mach number is higher in the steady simulation. To do this it is assumed that all entropy generation in the centre of the passage is as a result of the passage shock and the entropy is calculated upstream and downstream of the shock. From the change in entropy across the shock, and by using the Mach number relations for static pressure and static temperature ra- 


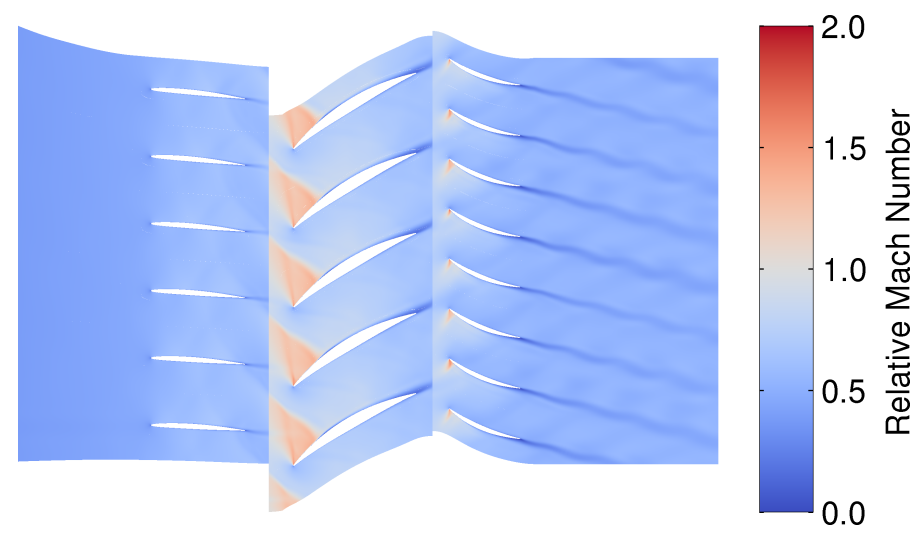

FIGURE 10: INSTANTANEOUS UNSTEADY RELATIVE MACH NUMBER AT 20\% SPAN FOR PRESSURE RATIO OF 1.63

tios across a normal shock, it is possible to calculate the Mach number normal to the shock. Using this method the Mach number, normal to the shock, calculated from the steady simulation is found to be 0.02 greater than the shock Mach number calculated from the unsteady simulation. The Mach number calculated from the entropy analysis is lower than the real Mach number because it represents only the component of the Mach number normal to the shock wave. The difference between the calculated Mach number and the real Mach number upstream of the shock means it is possible to calculate the angle of the shock wave and therefore the change in angle of the shock wave between the steady and unsteady simulations. The shock angle is found to change by 2 degrees, however, it should be noted that this is the change of angle assuming the shock wave is two dimensional when in practice it is three dimensional.

The stronger passage shock in the steady simulation has led to a stronger interaction of the shock wave with the boundary layer, which also contributes to the higher loss observed in the rotor for the steady simulations. The steady simulations under predicts the blockage in the rotor by $2 \%$ compared to the unsteady simulation as a results of a weaker tip leakage flow. The reduced blockage leads to a lower rate of acceleration on the suction surface of the rotor which in turn has led to a higher back pressure downstream of the leading edge shock wave and has pushed it upstream. The lower pressure on the suction surface downstream of the passage shock has pulled the passage shock downstream in the steady simulation.

When the rotor is operating close to stall, at a stage pressure ratio of 1.63, Fig. 10 shows that the passage shock has been pushed out of the rotor passage and has merged with the rotor leading edge shock. This can also be seen by looking at the surface isentropic Mach number shown in Fig. 11. The result of this is that the difference in the entropy rise across the rotor between

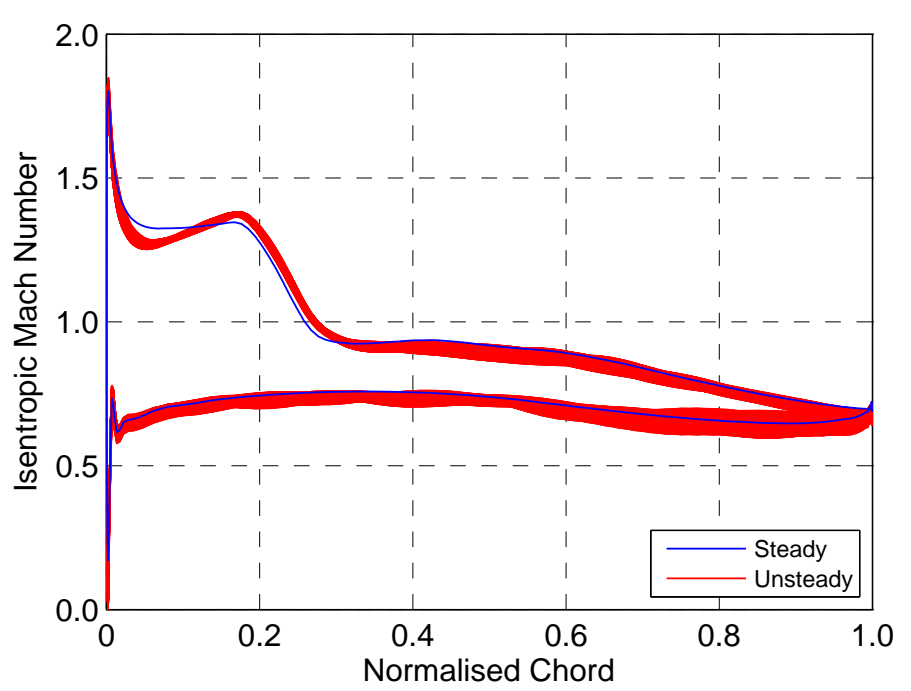

FIGURE 11: ROTOR SURFACE ISENTROPIC MACH NUMBER AT 20\% SPAN FOR PRESSURE RATIO OF 1.63

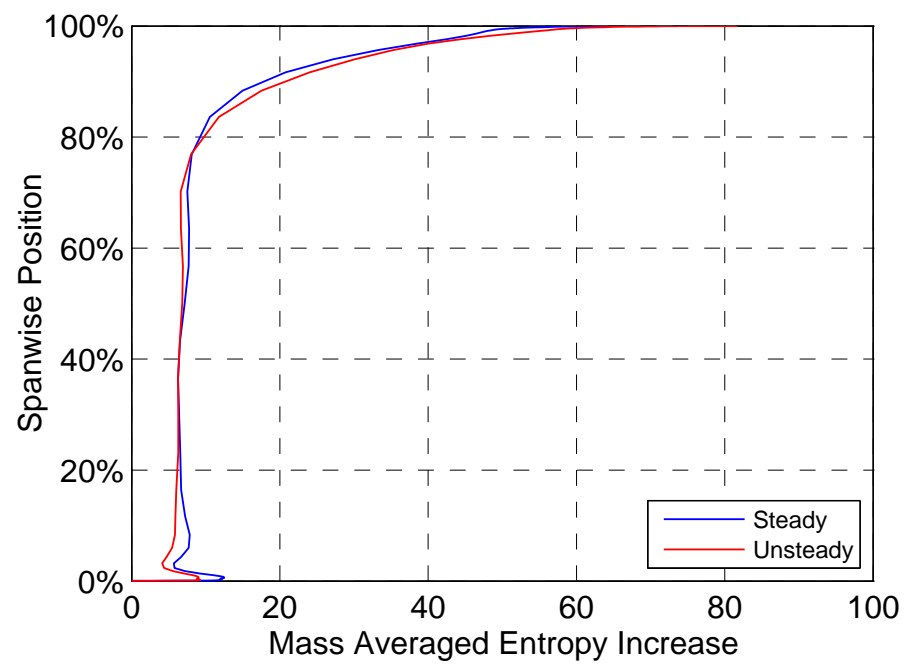

FIGURE 12: ENTROPY INCREASE ACCROSS ROTOR FOR PRESSURE RATIO OF 1.63

the steady and the unsteady simulations (seen in the lower half of the span in Fig. 7 when the rotor is choked) is no longer seen in Fig. 12 and as a result the efficiency delta for the rotor reduces when the stage pressure ratio increases, as seen in Fig. 6. There are however smaller differences between the steady and unsteady results near the hub and casing. Near the casing the steady simulation predicts less loss through the rotor which is due to a weaker tip leakage flow. Near the hub the steady simulation predicts a higher increase in entropy. This is due to a difference in the re- 


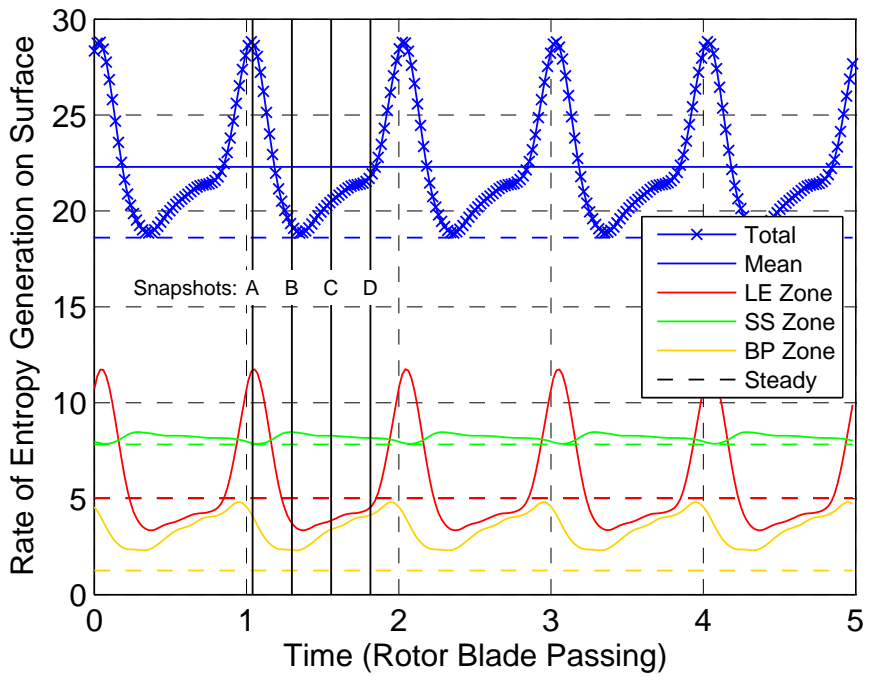

FIGURE 13: INTANTANEOUS ENTROPY GENERATION RATE FOR STATOR AT 80\% SPAN, SHOWN FOR TOTAL SURFACE AND LEADING EDGE (LE), SUCTION SUFACE (SS) AND BLADE PASSAGE (BP) SUMMATION ZONES

distribution of the mass flow across the span which results in a lower mass flow near the hub for the steady simulation and therefore a higher proportion of the mass flow in this region has come from the endwall boundary layer due to stronger secondary flow in the steady simulation.

\section{Stator Efficiency}

The stator efficiency in Fig. 6 is seen to drop off quickly at low pressure ratios. Comparing the flow field around the stator at high pressure ratios, shown in Fig. 10, and at low pressure ratios, shown in Fig. 8, it can be seen that the Mach number around the stator increases significantly at low pressure ratios and causes the drop off in efficiency. It is also at low pressure ratios that the stator efficiency delta increases to $1.2 \%$, from $0.7 \%$ near stall. This is a smaller variation than that for the rotor and the efficiency delta is positive (steady simulation predicts a higher efficiency than the unsteady simulation). To understand why this efficiency delta is present in the stator it is necessary to look how the unsteady inlet conditions to the stator affects the losses in the stator. The unsteady inlet conditions are caused by the rotor wakes and they have a large effect on the instantaneous loss generation in the stator.

To investigate this further the instantaneous rate of entropy generation on the surface at $80 \%$ span of a single stator blade is analysed for the steady and unsteady simulations at the peak efficiency pressure ratio. The total rate of entropy generation on this surface is shown, coloured blue, in Fig. 13 for 5 rotor blade passings. The entropy generation rate clearly varies with

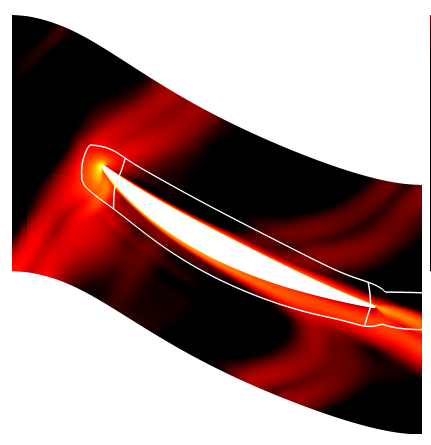

(a) SNAPSHOT A

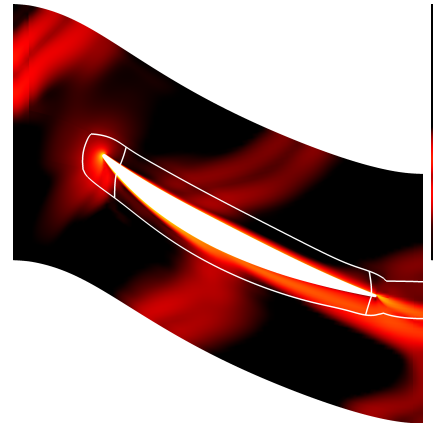

(c) SNAPSHOT C

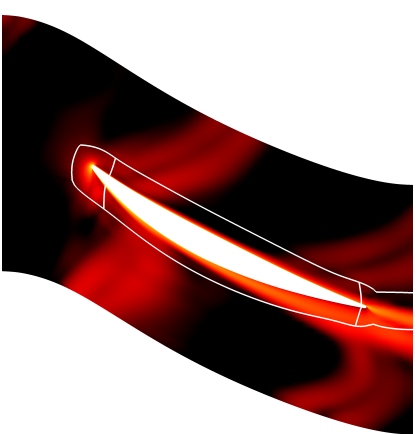

(b) SNAPSHOT B

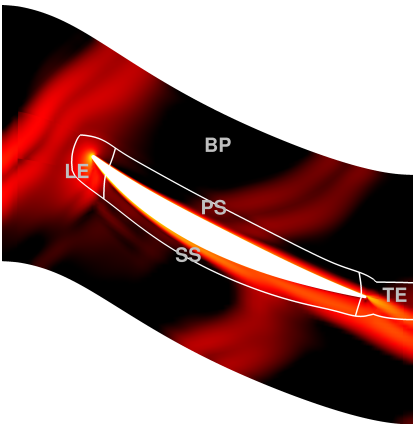

(d) SNAPSHOT D
FIGURE 14: LOGARITHM OF THE INSTANTANEOUS ENTROPY GENERATION RATE IN THE STATOR AT 80\% SPAN FOR 4 SNAPSHOTS WITH SUMMATION ZONES

the rotor passing frequency. The equivalent value for the steady simulation is also plotted in the dashed blue line and shows a much lower value than the mean unsteady value. This is consistent with the higher stator blade efficiency calculated in the steady simulations. To understand the wake-stator interaction in more detail the instantaneous entropy generation rate at $80 \%$ span has been plotted in Fig. 14 for 4 points in time across one rotor passing (snapshots A to D) showing the entropy generated by the stator boundary layers and the rotor wakes interacting with the surrounding fluid. In addition the entropy generation rate on this surface has been broken down into 5 summation zones covering the leading edge (LE), trailing edge (TE), suction surface (SS), pressure surface (PS) and the rest of the blade passage (BP). These zones are marked on the plots in Fig. 14 and the sum of entropy generation rate for the LE, SS, and BP zones is plotted in Fig. 13. The values for the PP and TE zones have very little variation across the cycle and so are excluded for clarity. The results in Fig. 13 show that the LE zone is the greatest contributor to the spikes in the total entropy generation rate. The peak occurs at Time A (Fig. 14a) when the rotor wake interacts with the stator leading edge. When the wake is not interacting with the LE (Fig. 14b, 14c \& 14d) the entropy generation rate in the LE zone for the steady simulation is higher than the value in the LE 

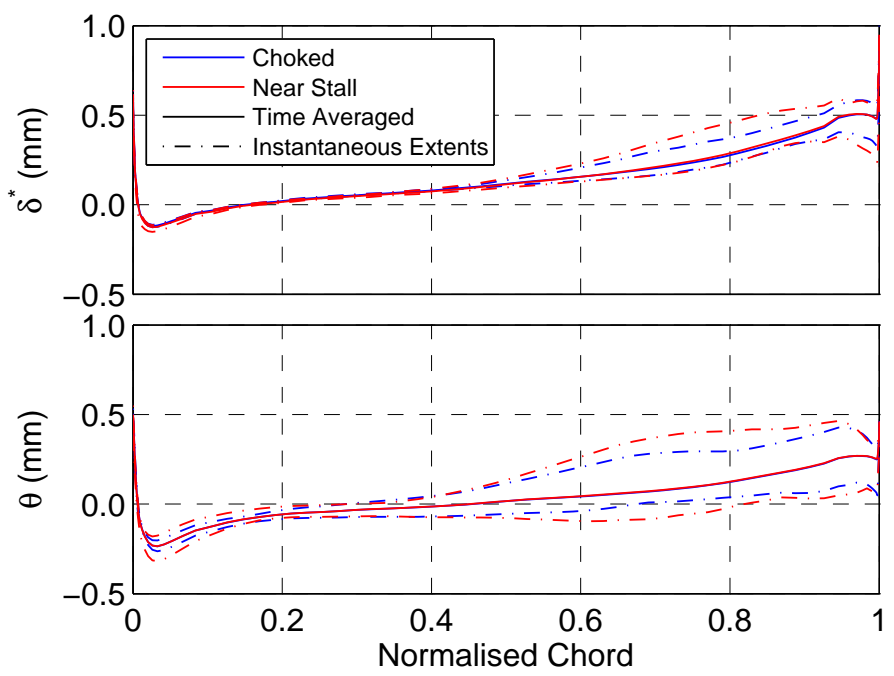

FIGURE 15: IGV SUCTION SURFACE BOUNDARY LAYER DISPLACEMENT AND MOMENTUM THICKNESSES AT $80 \%$ SPAN

zone for the unsteady simulation due to the difference in the inlet flow incidence. At Time B (Fig. 14b) the rotor wake has moved downstream of the leading edge and has a significant interaction with the suction surface. The wake causes a negative jet effect on the suction surface that extends the suction surface boundary layer away from the blade and increases the entropy generation rate. This can be seen in Fig. 14b and as a increase in the SS zone entropy generation rate in Fig. 13 at Time B. The steady value for the SS zone is equal to the minimum value for the unsteady SS zone as this corresponds to no wake interaction on the suction surface. The BP zone has the highest entropy generation rate when the maximum rotor wake mixing is captured in this zone and occurs between Time D and A. The entropy generation rate for the $\mathrm{BP}$ zone is lower in the steady simulation because there is no rotor wake mixing occurring in the stator passage in the steady simulation.

\section{IGV Efficiency}

The IGV blade efficiency in Fig. 6 is very similar between the steady and unsteady simulations for the whole pressure range except near stall where the steady simulation starts to give a slightly higher IGV efficiency. The increase in IGV efficiency at high pressure ratios is due to the reduction in the inlet Mach number as the stage approaches stall and the mass flow rate decreases. In the unsteady simulation this effect is counter acted by the effect of the stronger interaction between the rotor leading edge shock wave and the IGV which causes the IGV efficiency to stay almost unchanged. One way to see this increased interaction is to look at the boundary layer displacement thickness and mo-

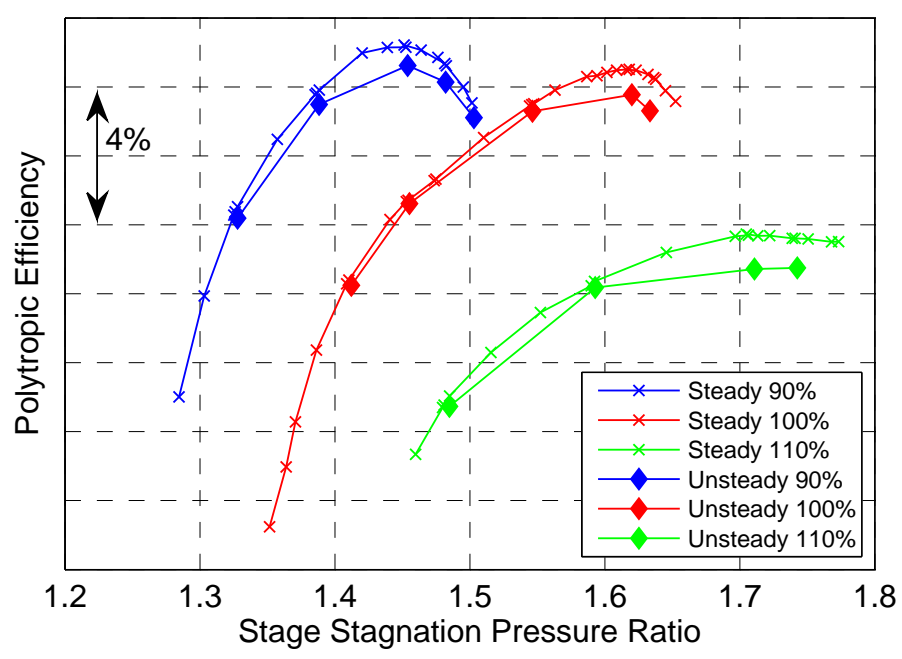

FIGURE 16: STEADY AND UNSTEADY EFFICIENCY PREDICTIONS FOR 1.5 STAGE CALCULATIONS

mentum thickness on the suction surface of the IGV. Figure 15 shows the IGV suction surface boundary layer displacement and momentum thicknesses for a choked simulation and a simulation near stall. The time averaged results are plotted in the solid line while the dash line marks the limits of the variation across the cycle. Although the time averaged results do not change much it can be seen that the variation in the displacement thickness and the momentum thickness is much greater near stall than when the stage is choked, showing that there is increased interaction with the rotor leading edge shock wave. The steady simulation over predicts the IGV efficiency because it is unable to capture the interaction between the IGV and the rotor.

\section{OFF-DESIGN SPEED ANALYSIS}

Figure 16 shows the stage efficiency for the compressor operating at $90 \%, 100 \%$ and $110 \%$ of design speed with results from steady and unsteady simulations. As with the calculations at design speed it can be seen that the steady simulations give a higher predicted efficiency for all pressure ratios. The efficiency delta increases as the operating point moves from low pressure ratios to peak efficiency in the same way as at the design speed. At part speed and over speed the efficiency delta reduces as the operating point moves from peak efficiency to near stall. This is opposite to at design speed where the efficiency delta continues to increase. The efficiency delta at peak efficiency for each operating speed increases as the operating speed increases.

The individual blade row efficiencies for $110 \%$ speed are plotted in Fig. 17. The largest difference from the design speed is that the stator efficiency drops significantly at pressure ratios above 1.65 . The drop off in efficiency is caused by a flow separa- 


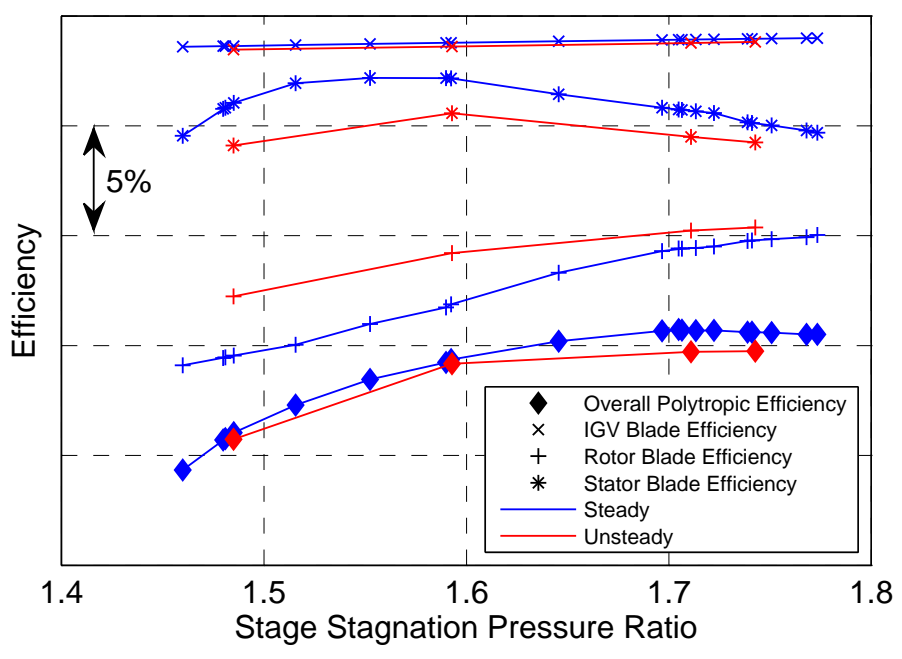

FIGURE 17: EFFICIENCY PREDICTIONS FOR INDIVIDUAL BLADE ROWS AT 110\% SPEED

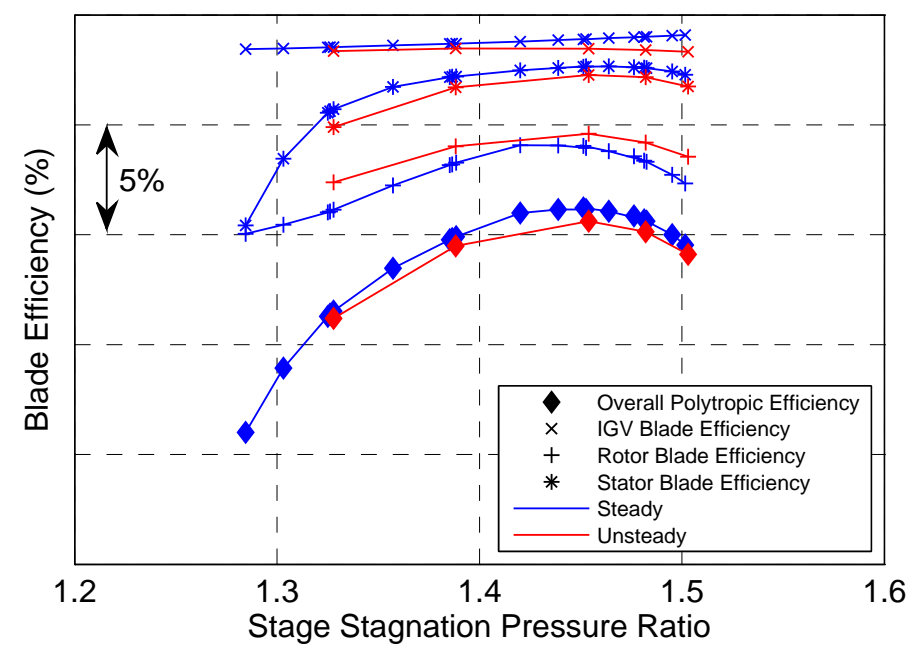

FIGURE 18: EFFICIENCY PREDICTIONS FOR INDIVIDUAL BLADE ROWS AT 90\% SPEED

tion occurring near the casing. The IGV efficiency does not vary between the steady and unsteady simulations, even at high pressure ratios. This is because at the higher axial Mach number, the compressor is pulling the shock structure further downstream, preventing it from fully exiting the rotor passage, even at high pressure ratios. This is also indicated by the fact that the rotor efficiency is still increasing at the highest simulated pressure ratio and has not yet reached the peak, suggesting that the shock structure will not be at its peak efficiency location and therefore not pushed out of the front of the rotor passage.

Figure 18 shows the blade row efficiencies for the compres-

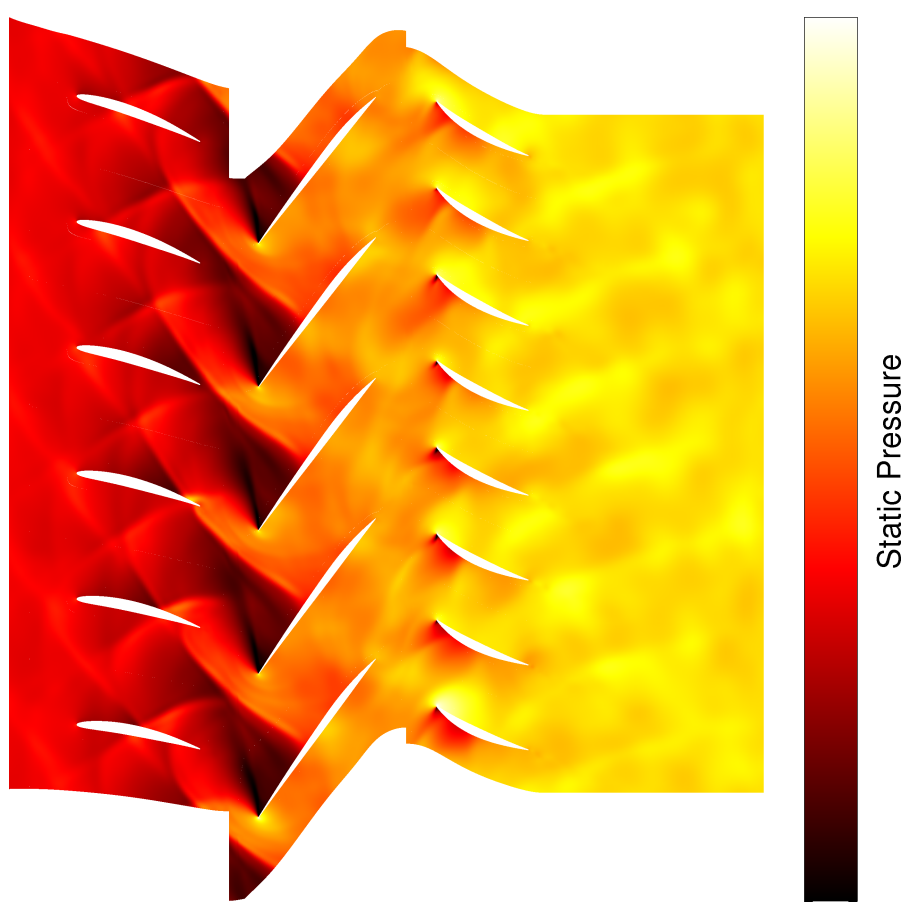

FIGURE 19: INSTANTANEOUS UNSTEADY STATIC PRESSURE AT $80 \%$ SPAN FOR NEAR STALL AT 90\% SPEED

sor operating at $90 \%$ speed. At high pressure ratios the rotor rolls past its peak efficiency and the rotor efficiency delta starts to increase again. At these pressure ratios, combined with the lower axial Mach number, the rotor passage shock has been forced out the front of the passages, as shown in Fig. 19. It can be shown that the greater efficiency in the unsteady simulation is due to a weaker shock wave by again performing a simple entropy analysis of the shock wave. This analysis shows an increase in the Mach number perpendicular to the shock from 1.23 in the unsteady simulation to 1.27 in the steady simulation. Given that the real Mach number upstream of the shock remains constant at 1.3 in both simulations the stronger shock in the steady simulation corresponds to a change in shock angle of 4 degrees relative to the flow. This change in angle results from a combination of the inlet flow angle changing and the absolute shock position moving. The shock waves, having being pushed out so far in front of the rotor, also have a greater interaction with the IGVs than at design speed. This can be seen as a significant increase in the variation of the IGV suction surface boundary layer displacement and momentum thicknesses from near choke to near stall, shown in Fig. 20. The variation that is present near stall at $90 \%$ speed is much greater than the variation seen at design speed in Fig. 15. The increased IGV efficiency delta at high pressure ratios arises because the steady simulations cannot model this interaction. 

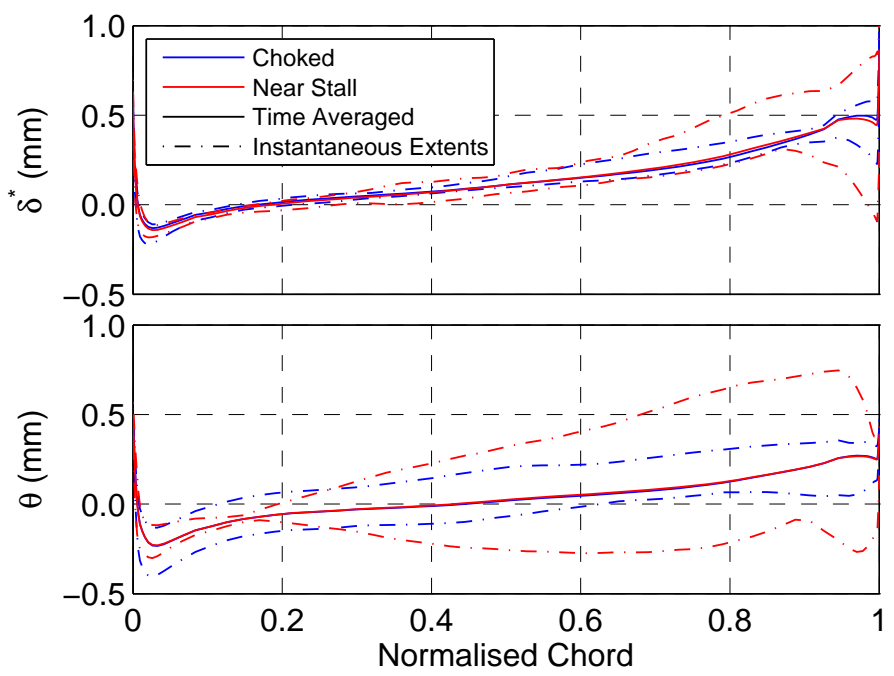

FIGURE 20: IGV SUCTION SURFACE BOUNDARY LAYER AT $80 \%$ SPAN FOR $90 \%$ SPEED

\section{EMBEDDED STAGE PERFORMANCE}

The whole 3-stage rig was simulated at once in order to analyse the effect of the downstream stages on the first stage. 3stage unsteady simulations were performed and the first stage efficiency was extracted and compared to the stage efficiency from the isolated stage simulations. It can be seen from the results in Fig. 21 that the presence of the downstream stages has virtually no effect on the efficiency characteristic for the first stage of the compressor. The operating point for the first stage of the compressor will still be affected by the downstream stage but for a given first stage operating point there can be confidence that the unsteady potential pressure field of the downstream stages will not alter the upstream stage performance. This is very important for the designer to know as it means that the stage can be designed without needing to be concerned that any unsteady effects from the downstream stages will significantly affect its performance.

\section{CONCLUSIONS}

Efficiency predictions for steady and unsteady simulations have been compared for a range of operating conditions at different speeds in order to give a better understanding of the effects that the assumptions involved in steady simulations, using the mixing plane approach, have on the predicted compressor performance. It has been found that steady simulations always give a higher predicted efficiency with a maximum over prediction of 1.05 percentage points towards high pressure ratio conditions. The over prediction at peak efficiency for a given speed is larger at faster speeds varying from 0.54 percentage points at $90 \%$ speed to 0.98 percentage points at $110 \%$ speed. The small

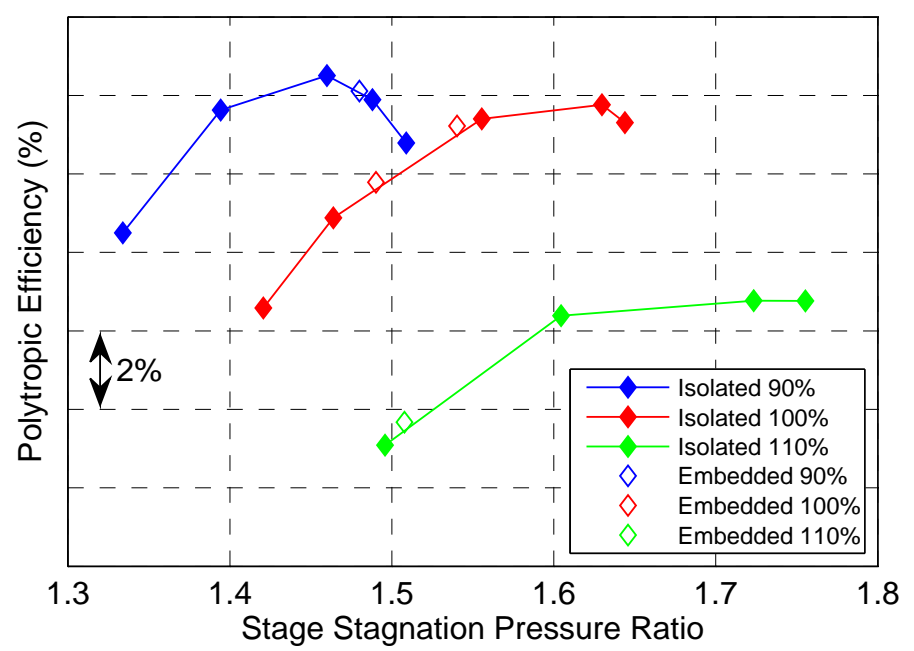

FIGURE 21: FIRST STAGE UNSTEADY EFFICIENCY FOR 3-STAGE AND SINGLE STAGE SIMULATIONS

efficiency delta at low pressure ratios $(<0.2$ percentage points $)$ is because the steady simulation under predicts the rotor efficiency and over predicts the stator efficiency, when compared to the unsteady simulations, and therefore cancel each other out. The steady simulations always give a lower rotor efficiency due to a stronger shock wave, and hence stronger interaction between the shock wave and the boundary layer, while the stator efficiency is always higher due to not modelling the interaction between the rotor wakes and the stator blades.

When the first stage is embedded within the 3-stage compressor, the simulation does not show any significant effect on the efficiency characteristics of the first stage. This means the designer does not need to give great consideration to the unsteady interaction effects of the downstream stages when designing the first compressor stage for the rotor speeds examined in this study.

$\begin{array}{ll}\text { NOMENCLATURE } \\ \bar{h} & \text { Mass and time averaged static enthalpy } \\ \bar{s} & \text { Mass and time averaged specific entropy } \\ \bar{T} & \text { Mass and time averaged static temperature } \\ y^{+} & \text {Non-dimensional wall distance } \\ \delta^{*} & \text { Boundary layer displacement thickness } \\ \Delta \eta & \text { Difference in efficiency between steady and unsteady } \\ \eta_{\text {blade }} & \text { Blade efficiency } \\ \eta_{p} & \text { Polytropic efficiency } \\ \theta & \text { Boundary layer momentum thickness }\end{array}$




\section{ACKNOWLEDGMENTS}

The authors would like to thank Siemens Industrial Turbomachinery Ltd, and EPSRC for funding this work and to Siemens for permission to publish it. Also to Dr Senthil Krishnababu, of Siemens Industrial Turbomachinery Ltd, for his helpful input.

\section{REFERENCES}

[1] Denton, J. D., 1992. "The Calculation of ThreeDimensional Viscous Flow Through Multistage Turbomachines". ASME, Journal of Turbomachinery, 114(1), pp. 18-26.

[2] Gourdain, N., Wlassow, F., and Ottavy, X., 2012. "Effect of Tip Clearance Dimensions and Control of Unsteady Flows in a Multi-Stage High-Pressure Compressor". ASME, Journal of Turbomachinery, 134(5), p. 051005.

[3] Ottavy, X., Courtiade, N., and Gourdain, N., 2012. "Experimental and Computational Methods for Flow Investigation in High-Speed Multistage Compressor". AIAA, Journal of Propulsion and Power, 28(6), pp. 1141-1155.

[4] Yamagami, M., Kodama, H., Kato, D., Tsuchiya, N., Horiguchi, Y., and Kazawa, J., 2011. "CFD Modeling Effects on Unsteady Multistage Simulation for a Transonic Axial Compressor". ASME Paper No. GT2011-46198.

[5] Yamagami, M., Kodama, H., Kato, D., Tsuchiya, N., Horiguchi, Y., and Kazawa, J., 2009. "Unsteady Flow Effects in a High-Speed Multistage Axial Compressor". ASME Paper No. GT2009-59583.

[6] Biesinger, T., Cornelius, C., Rube, C., Braune, A., Campregher, R., Godin, P. G., Schmid, G., and Zori, L., 2010. "Unsteady CFD Methods in a Commercial Solver for Turbomachinery Applications". ASME Paper No. GT201022762.

[7] Biesinger, T., Cornelius, C., Nürnberger, D., and Rube, C., 2012. "Speed Line Computation of a Transonic Compressor Stage With Unsteady CFD Methods". ASME Paper No. GT2012-68029.

[8] Prasad, A., 2003. "Evolution of Upstream Propagating Shock Waves From a Transonic Compressor Rotor". ASME, Journal of Turbomachinery, 125(1), pp. 133-140.

[9] Arnone, A., and Pacciani, R., 1998. "IGV-Rotor Interaction Analysis in a Transonic Compressor Using the NavierStokes Equations". ASME, Journal of Turbomachinery, 120(1), pp. 147-155.

[10] Chen, J., Hathaway, M. D., and Herrick, G. P., 2008. "Prestall Behavior of a Transonic Axial Compressor Stage via Time-Accurate Numerical Simulation". ASME, Journal of Turbomachinery, 130(4), p. 041014.

[11] Sun, Y., Ren, Y., Fu, S., and Wadia, A. R., 2008. "The Unsteady Loss in One-Stage Transonic Compressor Under Peak Efficiency and Near Stall Conditions". ASME Paper No. GT2008-51019.
[12] Probasco, D. P., Leger, T. J., Wolff, J. M., Copenhaver, W. W., and Chriss, R. M., 2000. "Variations in Upstream Vane Loading With Changes in Back Pressure in a Transonic Compressor". ASME, Journal of Turbomachinery, 122(3), pp. 433-441.

[13] Herrick, G., Hathaway, M., and Chen, J., 2009. "Unsteady Full Annulus Simulations of a Transonic Axial Compressor Stage". AIAA Paper No. 2009-1059.

[14] Hah, C., Puterbaugh, S. L., and Copenhaver, W. W., 1997. "Unsteady Aerodynamic Flow Phenomena in a Transonic Compressor Stage". AIAA, Journal of Propulsion and Power, 13(3), pp. 329-333.

[15] Leichtfuss, S., Biela, C., Schiffer, H., and Heinichen, F., 2012. "Influence of Inlet Guide Vane Wakes on the Passage Flow in a Transonic Axial Compressor". ASME Paper No. GT2012-69485.

[16] List, M. G., Gorrell, S. E., and Turner, M. G., 2010. "Investigation of Loss Generation in an Embedded Transonic Fan Stage at Several Gaps Using High-Fidelity, Time-Accurate Computational Fluid Dynamics". ASME, Journal of Turbomachinery, 132(1), p. 011014.

[17] Gorrell, S. E., Car, D., Puterbaugh, S. L., Estevadeordal, J., and Okiishi, T. H., 2006. "An Investigation of WakeShock Interactions in a Transonic Compressor With Digital Particle Image Velocimetry and Time-Accurate Computational Fluid Dynamics". ASME, Journal of Turbomachinery, 128(4), pp. 616-626.

[18] Hah, C., 2015. "Effects of Unsteady Flow Interactions on the Performance of a Highly-Loaded Transonic Compressor Stage”. ASME Paper No. GT2015-43389.

[19] Li, Y. S., and Wells, R. G., 1999. "The Three-Dimensional Aerodynamic Design and Test of a Three-Stage Transonic Compressor". ASME Paper No. 99-GT-068.

[20] Brandvik, T., and Pullan, G., 2010. "An Accelerated 3D Navier Stokes-Solver for Flows in Turbomachines". ASME, Journal of Turbomachinery, 133(2), p. 021025.

[21] Denton, J. D., 1983. "An Improved Time-Marching Method for Turbomachinery Flow Calculation". ASME, Journal of Engineering for Power, 105(3), pp. 514-521.

[22] Spalart, P. R., and Allmaras, S. R., 1994. "A One-Equation Turbulence Model for Aerodynamic Flows”. La Recherche Aerospatiale, 1, pp. 5-21.

[23] Jameson, A., 1991. "Time Dependent Calculations Using Multigrid, With Applications to Unsteady Flows Past Airfoils and Wings". AIAA Paper No. 91-1596.

[24] Denton, J. D., 1993. "The 1993 IGTI Scholar Lecture: Loss Mechanisms in Turbomachines". AMSE, Journal of Turbomachinery, 115(4), pp. 621-656. 